\title{
Advocating for integrative medicine: providers' stories of resonance, negotiation, and community
}

\author{
Courtney Hook, ${ }^{1}$ Brielle Plump, ${ }^{2}$ Patricia Geist-Martin ${ }^{3}$ \\ ${ }^{1}$ Scripps College of Communication, School of Communication Studies, Ohio University, Athens, OH; ${ }^{2}$ Department of Language \\ Arts/Communication, Skyline College, San Bruno, CA; ${ }^{3}$ School of Communication, San Diego State University, San Diego, CA, USA
}

\begin{abstract}
Integrative medicine (IM) is a holistic health care option that blends complementary, alternative medicine with biomedical models of care. Many medical care facilities do not offer IM treatment for patients, yet the demand for IM is growing. Therefore, IM providers are in the position of educating and promoting IM to patients and other medical practitioners. There is limited research literature focusing on how IM providers communicate advocacy for IM. Therefore, this research is designed to explore the perspectives of providers about the ways that they communicate advocacy for IM in their lives and their medical practice. Interview data we collected at The Center reveals the ways that IM providers continuously advocate for IM through their resonance with IM philosophy, by negotiating systemic tensions that revolve around IM, and by forming communities of practice with patients and other providers. Results of this investigation offer insight about IM, communication, and advocacy.
\end{abstract}

\section{Introduction}

Holistic health care can be traced back centuries, with some scholars naming Aristotle as the first holistic physician, who understood people as a combination of spiritual and physical properties. ${ }^{1}$ The word holism was first used to describe medicine in $1952,{ }^{2}$ and has since evolved from being a popular movement in the 1960 s and 70 s to being considered a professionalized entity in recent decades. ${ }^{3}$

Correspondence: Courtney Hook, Scripps College of Communication, School of Communication Studies, 400 Schoonover Center, 20 E. Union Street, Athens, Ohio 45701, OH, USA.

Tel.: 740.593.4828 - Fax: 740.593.4810.

E-mail: ch915217@ohio.edu

Key words: Integrative medicine; Narratives; Advocacy; Health; Qualitative research.

Contributions: the authors contributed equally.

Conflict of interest: the authors declare no potential conflict of interest.

Received for publication: 4 September 2017

Revision received: 10 April 2018.

Accepted for publication: 10 April 2018.

This work is licensed under a Creative Commons Attribution NonCommercial 4.0 License (CC BY-NC 4.0).

CCopyright C. Hook et al., 2018

Licensee PAGEPress, Italy

Qualitative Research in Medicine \& Healthcare 2018; 2:30-44

doi:10.4081/qrmh.2018.7049
Although the term holistic is often used as an all-encompassing word for complementary and alternative medicine (CAM) ${ }^{4}$ integrative medicine (IM) is a term that blends alternative, complementary, and conventional, biomedical practices with a focus on patient-centered care. IM places emphasis on the collaboration between patients and providers and relies on evidence-based scientific thinking. ${ }^{5}$ IM providers encourage patients to take personal responsibility for their own health while advocating for the merits of integrative approaches that combine IM and biomedicine.

IM providers often offer patients options for less expensive and less invasive medical treatments through integrative approaches of care, but not as a replacement for biomedicine. IM physicians therefore become advocates for their practice, where they recognize and embrace the interaction between mind, body, and spirit in health and healing. In a comprehensive survey of IM centers in the U.S., researchers identified over 60 centers that exist to focus on integrative care across America. ${ }^{6}$ With over a million medical doctors currently practicing in America, it is not surprising that IM providers become advocates for their philosophies and medical practices as a normative approach to care.

This study is designed to explore the perspectives of providers about the ways that they communicate advocacy for IM in their lives and their medical practice. Analysis of IM providers' narratives reveal their philosophy of IM, in addition to when and where they advocate for IM. We begin with a brief review of literature about IM. Next, we offer a description of the methodology utilized for this research. Then we present the results of this investigation. Finally, we close with a discussion of these results, including conclusions, implications, and directions for future research. 


\section{The history of and advocacy for integrative medicine}

IM has had a long history, evolving from the recognized value of holistic approaches to health care. Advocacy for IM has increased as both patients and providers have recognized the importance of integrating biomedicine with complementary, with complementary approaches. Inevitably, IM practitioners become advocates for IM in their lives and in their practice of medicine.

\section{Integrative medicine: origins, evolution, and critiques}

IM is a complex, multifaceted approach to health care. The Bravewell Collaborative ${ }^{5}$ defines IM as care that puts the patient at The Center and addresses the full range of physical, emotional, mental, social, spiritual, and environmental influences that affect a person's health (p. 6). This holistic approach to health is healing-oriented and relationship-centered, focusing on minimal invasion, toxicity, and cost to the patient. ${ }^{1}$ IM is sometimes discussed in contrast to the biomedical approach, which has been termed the traditional, conventional, or Western model of care. Biomedicine is the predominant model taught to and used by physicians, focusing primarily on physiology, biochemistry, genetics, and other basic or so-called 'hard sciences. ${ }^{7}$ This dominant model of care approaches health through a scientifically-principled lens, representing one of many reasons biomedicine is often dichotomized from IM.

IM does not function in lieu of biomedicine, however. Scholars have argued against the bifurcation of biomedicine and IM, encouraging patients and providers to treat both paradigms as complementary to one another. ${ }^{8}$ Further, IM is only one branch of various holistic practices, including, but not limited to, acupuncture, nutrition, meditation, yoga, and music therapy. It is critical to understand that, although these terms are often used interchangeably, each holds a unique relationship with conventional medicine. According to the National Center for Complementary and Integrative Health, ${ }^{9}$ complementary medicine refers to conventional medicine used in conjunction with non-mainstream practices whereas alternative medicine signifies the replacement of conventional medicine with non-mainstream practices. CAM is particularly important to understand when defining IM, which integrates the mission of complementary medicine through the mindful collaboration of conventional and complementary strategies. As Baer ${ }^{3}$ indicates, IM refers to efforts on the part of conventional physicians to blend biomedical and CAM therapies or the collaborative efforts between biomedical physicians and CAM practitioners to address health care needs of specific patients (p. xiv). IM is therefore a collaborative effort that integrates biomedical strategies with CAM modes of care.

IM has gained increasing popularity over the years from practitioners and patients alike. According to a survey conducted by the U.S. Department of Health and
Human Services, $33.2 \%$ of adults and $11.6 \%$ of children in the United States use complementary health approaches..$^{10}$ To address the multifaceted nature of IM, the Bravewell Collaborative ${ }^{5}$ established several principles of IM, including: i) a relational partnership between patients and practitioners; ii) the holistic consideration of health, wellness, and disease; iii) care centered around mind, body, and spirit; iv) an emphasis on healing sciences as a catalyst for the body's innate abilities; v) more natural, less invasive interventions; vi) individualized and prevention-focused care; and vii) IM practitioners exemplification of IM principles through commitment to self-development and self-exploration. Throughout what Fadlon ${ }^{11}$ has coined the holistic turn, patients, providers, and medical facilities have spent the past several decades creating and refining these principles through the implementation of new ways to use biomedical modalities, while offering less invasive, less expensive treatments. ${ }^{1}$ Importantly, IM was not IM was not intended to replace biomedicine, but work in conjunction with traditional methods where both modalities rely on evidence-based approaches and patient-centered wellness.

Collaboration between biomedicine and IM has not been as fluid or amicable as proponents of IM would like. Early on in the introduction of IM, biomedical practitioners were accused of incorporating alternative medicine into their own practices to serve the purpose of preserving the hegemony of medicine by co-opting the most attractive components of holism. ${ }^{12}$ Research reveals that tensions exist in collaboration, legitimacy, consistency, and unification between biomedical and integrative providers, often due to a lack of support from the health care system $;{ }^{13}$ research is needed to understand how collaboration might occur between varied health models. ${ }^{14}$ However, increasingly biomedical providers seem to be in favor of institutional integration and collaboration with IM providers. ${ }^{15-17}$

Since its establishment, IM has faced harsh and, in many cases, unfounded criticisms. In addition to macrolevel tensions and institutional constraints surrounding the inclusion of IM into biomedical health care settings, patients and physicians find they must defend the use of and need for IM on a day-to-day basis. As more and more physicians and patients utilize IM, they discover ways to negotiate these tensions to negotiate these tensions by becoming advocates for integrative approaches to health.

\section{Advocacy in health care settings}

Advocacy has been studied in a variety of health contexts, with research focusing on interpersonal advocacy, self-advocacy, and institutional advocacy. Interpersonal advocacy literature emphasizes how loved ones function as advocates for their family members, romantic partners, or children. In health care settings, interpersonal advocacy 
can occur when partners advocate for one another during cardiology office visits, ${ }^{18}$ when parents advocate for children suffering from complex chronic illnesses, ${ }^{19}$ and when mothers become a voice for their children with down syndrome. ${ }^{20}$ Research has also addressed self-advocacy behaviors among long-term cancer survivors, ${ }^{21}$ patients with AIDS, ${ }^{22}$ and young students with developmental disabilities. ${ }^{23}$ Finally, research reveals how institutional advocacy occurs in organizations like Planned Parenthood ${ }^{24}$ and Relay for Life. ${ }^{25}$

Advocacy plays an integral role in communication surrounding IM between patients and physicians. ${ }^{26} \mathrm{Un}-$ fortunately, research has found that patients who believe in IM are hesitant to disclose their use of CAM to primary physicians. A 2011 survey by AARP and NCCAM - available from: https://nccih.nih.gov/sites/nccam.nih.gov/ files/news/ camstats/2010/NCCAM_aarp_survey.pdf exploring disclosure between people aged 50 or older and their health care providers revealed that nearly half of participants $(47 \%)$ reported using CAM within the past 12 months, but only one-third discussed CAM with their health care provider. Further, patients were twice as likely to initially bring up CAM than their physician, which aligns with the notion that patients don't bring it up because providers don't ask. ${ }^{27,28}$ In a comprehensive review of literature assessing patient disclosure of CAM to medical practitioners, Robinson and $\mathrm{McGrail}{ }^{28}$ discovered the most common reason why patients do not disclose CAM to conventional providers is fear of receiving a negative response. Ironically, research reveals that $90.9 \%$ of people were found to discuss biomedical treatments with their naturopathic providers. ${ }^{27}$ Scholars concerned with low patient disclosure regarding CAM use have explored patient education interventions, which have been found to help patients become more proactive and effective in conversing with practitioners about CAM. ${ }^{29}$ Although health care systems have come a long way in the integration of complementary medicine with biomedicine modalities, progress still needs to be made in how patients communicate advocacy for CAM and IM.

Patient advocates of IM are often most focused on taking responsibility for their health and well-being. ${ }^{1}$ Willard ${ }^{30}$ contends those who follow integrative medical practices take control of their bodies. They do not place the fate of their bodies in the hands of a professional; rather, they participate in the creation and management of their health (p. 141). While this notion is written about patients, we believe IM practitioners experience similar turning points in which they are left to take control of their professional fate. In the face of institutional and societal criticism, IM practitioners often become advocates for themselves and their practice of IM, yet there is limited research focusing on providers' perspectives of their advocacy of IM. We believe this perspective is best illuminated through providers' narratives, wherein IM practitioners tell stories of their initial interests in IM and how those interests manifested in their educational and professional experiences.

\section{Understanding advocacy through narrative}

While some conventional health care stakeholders may still believe that holistic, alternative, complementary, and IM are illegitimate modalities of health, it is clear that IM practitioners find themselves in the position of communicating advocacy for patient-centered health that centers around mind, body, and spirit. IM providers become proponents of embodied health care while living as embodied characters in narratives that identify and divide, cooperate and compete, perform and motivate. ${ }^{31}$ Providers' experiences and stories of practicing IM in predominantly biomedical settings reveal internal and external struggles that they face in attempting to legitimize their prescribed methods. ${ }^{13}$ Advocacy is rooted in seeking commitment and support from others; being an advocate implies gaining political commitment and policy support through organized social action with the involvement of committed individuals, support from influential forces and the involvement of concerned sectors of society (p. 48). ${ }^{32}$ It becomes interesting to consider the ways in which providers accomplish advocacy in health settings that are predominantly staffed by providers with no IM training or who do not believe in IM.

Therefore, in an effort to better understand how IM providers perceive the ways they communicatively construct moments of advocacy, this research focuses on the following question:

RQ: What do the narratives of IM providers reveal about their advocacy for IM?

\section{Methods}

This research is designed to investigate how providers describe the ways they communicate advocacy for IM. The interviews for this research were conducted with providers practicing IM in a center for IM.

\section{The research site}

The Center (pseudonym) is part of a larger medical system that operates under a standard biomedical model of care via five campuses, a network of clinics, and over 2600 affiliated physicians. The Center houses approximately twenty providers, eight of whom are medical doctors (MDs), twelve of whom are nurses, IM providers (e.g., acupuncture, nutrition, biofeedback, guided imagery, healing touch, and hypnosis, to name a few), and instructors of IM classes (yoga, meditation, vegetarian cooking, Qigong, and Tai Chi to name a few). The Center serves over 2,500 patients monthly who typically access the Center via referrals from The Hospital.

The Center stands apart from the health care system it serves, located in a separate building, miles away from 
any of the five five main campuses. The Center was founded upon the philosophy that healing starts from within, and aims to blend evidence-based complementary and alternative therapies with conventional Western medicine in a 'best of both worlds' approach. People visiting The Center may be seeking treatment and relief for a range of illnesses, including cancer, diabetes, heart disease, weight management, gastro-intestinal concerns, acute or chronic pain relief, or stress; however, the Clinic began through an effort to offer IM treatments specifically to cardiology patients.

\section{Participant information and recruitment}

The Center agreed to participate in this research study with Internal Review Board approval and under the supervision of one primary provider at The Center. Nine providers at The Center agreed to be interviewed. Of the nine providers, three are registered nurse practitioners and six are MDs. Of the MDs, four are cardiologists, and two are family medicine practitioners. All providers have additional training, certifying them as IM Specialists, and have selected interests in pain management, acupuncture, biofeedback, hypnosis, reiki therapy, or other IM modalities. The sample included five females and four males. No age or racial demographics were officially collected for this study, at the request of participants.

\section{Interview data collection}

We extended our initial invitation to providers to participate in our study at one of their weekly meetings. We followed up by contacting providers via email or telephone. Once participants replied to our correspondences and scheduled appointments, interviews were conducted at The Center or in nearby locations at the convenience of participants.

The narrative interviews were open-ended, encouraging providers to tell stories about their interest and training in IM and their experience in providing IM at The Center. ${ }^{33}$ The interviews ranged in length from thirty minutes to an hour and forty-five minutes. We conducted several interviews with three specific providers because of their extensive roles either as our key informant coordinating our study or because of their roles as outgoing or incoming Director of The Center.

\section{Data analysis}

Once all interviews were transcribed, our data set included over ten hours of audio content and 167 pages of transcripts. We engaged in narrative analysis of the transcripts, locating the stories providers tell about advocacy, assuming that narratives or stories hold special powers as windows into the individual and social world (p. 4). ${ }^{34}$ Our narrative analysis of the data occurred through three phases. Phase One involved all three authors reading through the complete set of transcripts and open-coding excerpts of discourse where providers offered stories of some form of communicating advocacy for IM. In Phase Two, the authors dialogued about their independent version of the patterned ways that the providers communicated advocacy for IM. Through this extended conversation, the authors identified and agreed upon the stories that represented three categories of communicating advocacy: i) advocacy as resonance with the mission of IM; ii) advocacy as negotiation of dialectic tensions; and iii) advocacy as the formation of communities of support. In Phase Three, each author, responsible for one of these three categories, returned to the transcripts to locate stories that represented that category. As much as possible, we made an effort to include the voices of all nine providers. The results of this research, presented in the next section, elaborate the meanings of communicating advocacy in each of the three categories.

\section{Communicating advocacy for integrative medicine}

Trailblazing is a word that is often used to describe the work that providers engage in to advocate for the use of IM. ${ }^{35}$ First, the results of this investigation reveal that providers communicate advocacy for IM because they resonate with its mission. Second, providers find themselves continuously constructing and communicating this advocacy in their provision of health care because of the challenges or tensions that often exist in the health care system. Finally, providers discover that their advocacy is communicated and maintained through the formation of community with others, including providers, patients, and the public. Each of the subsections that follow offer the stories providers tell that offer evidence of these three ways of communicating advocacy.

\section{Advocacy begins with providers' resonance with the mission of integrative medicine}

All nine of the providers in this study spoke of the ways that they became advocates for lifestyle changes and healing modalities that consider the whole person. They speak of something that occurred in their families, their socialization in medicine, a personal experience or pivotal moment, or just how they feel different in some way. For most, these were foundational ideas they continue to draw upon in their work as MDs as nurses, or as CAM practitioners.

One of the predominant foundations that establishes providers' advocacy for IM is familial resonance. These stories reveal experiences with family members that set the stage for their advocacy. One provider describes how influential his grandparents were:

You know, it started with my grandparents. They are very, very - you know, they were considered like the health nuts of our family. You know, there was like a funny joke about them when I was younger. But as I 
got older I understood that they actually knew what they were doing. They were big into complementary alternative medicine. I learned a lot just kind of growing up in their house about you know, healthy, not healthy, the things that they did. I mean they - yeah. They avoided doctors forever. You know, so that's kind of where it started.

Hughes spoke of the ways that his approach to medicine is to focus on lifestyle one-on-one with his patients; in his words, I'm not going to call it coaching, but you know, it just has to change or else the system is going to break and I think integrative is the way it's going to end up. But grandparents were not the only family members that played a foundational role in providers' advocacy.

Four other providers talked about the ways that parents influenced their advocacy for IM. Silverman suggested that his advocacy began with his dad's career:

My dad was a botanist so I think I had some interest in plants and stuff so. But when we came here, I really started working here without knowing much about integrative medicine.

Providers of IM speak of the value of supplementing biomedicine with healing through plant-based nutrition, as well as Chinese herbal medicine that uses different parts of plants to create teas, capsules, and liquid extracts. It is clear that this was an important foundation for Silverman. This philosophy was also instrumental for Iverson through her upbringing in an Asian country:

So my parents definitely instilled within me the foundations of good health as really the foundations of living in a healthful way. And they didn't believe in using medications unless it was absolutely necessary.

Familial resonance became the foundation for a focus on IM for two of the providers because of their experience with family illness or death. Tali believes his advocacy is tied directly to his father's death:

I wanted to do medicine because of my dad's history, we were in and out of the hospital forever... [My first year of] residency is when my father passed away. It just didn't make sense to me... He had had open heart surgery for valve replacement, back surgeries, he had had all of his lung cancer site, he had afib, he had a pacemaker...but he was on all the right medicines and insulin and still died and I was sitting there when he died just scratching my head like where did we go wrong.

In Tali's view, the problem was, not one doctor ever talked to him about the way he eats, what he was eating, about what he was not doing for exercise, about his weight problem. So, with this familial history, it is not surprising that as an IM cardiologist, Tali's specialty is in lifestyle management and nutrition.

One other provider who is a cardiologist describes the early deaths of her mother and brother as the beginnings of her understanding of the heart and cardiology as more than its biological functioning.
I've kind of got a lot of loss in my early life. You know, I lost my mom when I was 8, my brother when I was 10, so I realized the importance of grief, and when I work with my patients, I really understand, you know, it got me thinking that broken heart is so much more than just oh gee, I have high cholesterol, and of course, the research supports that, right? So it made me aware of the dynamics that go on in families when there's loss, when there's grief, when someone is ill, you know, all of these things.

Halloway tells us that as a cardiologist she is always thinking about what she needs to do to keep people healthy: Well I need nutrition, I need exercise, I need people to transform the way they respond to stress and tensions, whether it's through prayer, yoga, meditation. She found that it was her own trauma and her experience of putting in stent after stent as a cardiologist that led her to advocate for what can be done for patients, besides drugs, and within families to help prevent coronary disease in the first place.

Familial resonance was not the only foundation for providers' advocacy for IM. Five providers talked about the ways they felt different than others and that difference was foundational in feeling resonance with and advocating for any and all ways to offer healing and health to patients. Halloway talks about the need she felt to do medicine differently:

So all of these things and witnessing all of these things have really made me say, you know, we need to do medicine differently. We can't just keep putting in stents and giving people drugs. I mean that's what I was doing, and we need to complete the circle of care, which is what led to the birth of [The Center].

Halloway tells us that she is different than most doctors: I will never be a doctor that sees a patient every 15 minutes, get them in, get them out...I would rather go back to the old fish doctor's office, to be honest with you, and get paid in eggs than practice medicine [that way]. Tali tells us that he didn't know he was interested in IM, but that he knew that what he believed in about medicine was different than most doctors:

I was just interested in more lifestyle, which is still my big focus. You know, with all the different aspects of IM from energy work to different mind-body modalities to supplements etc., the lifestyle stuff of eating right, exercise and good coping with stress and anxiety and depression, that's my passion.

Whether it is a passion or just a feeling, most of the providers in our study found themselves drawn to IM in a magical kind of way. Hadley speaks in the same voice as many of the providers when she tells us:

I don't know if you've had people tell you, but I think many of us have a strong belief that people find their way here for a reason, even the staff as well as the patients...I heard talk of starting an IM center, and I don't know. I can't tell you what it was. I just knew it was a feeling of yes, this is where I need to be. 
For some providers, the sense that there was another way of looking at things began much earlier, in some cases before they were even thinking about medical school.

Two of the providers described feeling different or feeling drawn to something different and wanting to look at things from a different paradigm. Carson, the only provider we interviewed that began in IM and then became an MD says this:

In high school and college, I became very interested in eastern philosophy and so I think that was sort of the gateway of there's this whole other way of looking at things. So I began doing meditation, tai chi, and one of my professors said, you know, you should do a fellowship which allows you to go study other healthcare systems, knowing I was premed and going into this healthcare system.

For another provider, Morris, this whole other way of looking at things was part of his personality growing up:

So then I go into residency and I mean these things are still in my head. I mean I was always kind of a goofy kid with strange ideas and, you know, interested in supernatural and whatever, you know? All the strange sci fi and stuff. So that's kind of the paradigm that I came in to this with was, you know, this Star Trek mentality...I was very interested in like metaphysical approaches and the mind, what is the mind and so I was very abstract in my thought process.

Morris goes on to say that I always think outside of the box...I can't think in a box and I can't function that way. Like many of the other providers in this study, he began to look for things that connected with the paradigm that resonated with his personality.

What we learn then in this first category is that advocacy for IM begins with providers' resonance with the mission of IM. Sometimes that resonance is something that returns them to their upbringing, a parent's or grandparent's philosophy, or a unique personality trait. Other times, it can be a pivotal moment or a personal experience where their passion clicks in, and they feel this strong resonance with IM. Their voices speak in unison as resonance with listening to people's stories, considering the whole person and how they live their lives, partnering with and empowering people, and placing an emphasis on lifetime learning.

The second category of communicating advocacy for IM reveals that it isn't always and easy road to hoe - that providers' advocacy is continuously constructed by negotiating systemic dialectic tensions.

\section{Advocacy is continuously constructed in negotiating dialectic tensions}

Trailblazing for IM providers translates to continuous negotiation of remnant and real dialectic tensions communicated in a health care system that values evidencebased medicine as historically represented well in biomedicine and more recently in CAM. IM has been described as a successful bridging of biomedicine and CAM, but not without polarizing qualifications that are oversimplified ${ }^{36}$ and challenges to collaboration that are vital for integration..$^{13}$ In this second category of communicating advocacy we focus on what we have located in providers' narratives as the predominant dialectic tensions they negotiate with other providers, patients, families, and the general public. These interactions become avenues for advocating for IM and their ideology of care.

Communicating about these tensions does not necessarily pit biomedicine and CAM against one another, but instead the tensions reveal opportunities to open up dialogue and advocate for health care reform. As Todorov ${ }^{37}$ suggests about stepping outside of the frame of them versus us: the relations between $A$ and $B$ are in a state of permanent formation and transformation; they continue to alter in the very process of communication (p. 55). Providers in this study put into words their conceptualizations of these tensions and conversations they have with others about these tensions; in the process, the providers voice their visualization of the transformations in medicine they believe in, enact, and advocate for in the evolution of the health care system. The two subsections that follow offer providers' stories of two prominent tensions. Their communication reveals the ways that powerful economic and political interests still dominate the context of $\mathrm{IM}^{13,38}$ and as a result, the tensions they must face enacting and advocating for IM. What is clear is that there is a fine line between each of these two tensions; they overlap in many ways as revealed in our discussion of each.

\section{Health-care with disease-care}

Providers' voice their interest in integrating biomedicine with the CAM modalities - integrating health-care with disease-care. However, a tension exists in trying to accomplish both - the tension is often referred to as occurring between science and compassion or education and cost. Part of the problem as Halloway states is that the incentive in the health care system is on enacting a protocol that focuses on the disease and reimbursement without engaging in health-care (e.g., prevention or lifestyle education), which is typically not reimbursed:

You must remember healthcare is not healthcare, it's disease care. And it is still today, God willing it will change. But medicine is incentivized, physicians are incentivized for doing things for people, right. So I'm going in-you know, if you're a cardiologist that practices lifestyle change versus a cardiologist that's putting in stents, the lifestyle change cardiologist is making maybe a third of the money, maybe less.

It is not surprising then that these providers believe in disease-care WITH health-care, which Morris describes in this way:

And to me, it really just means that you're using the best of what's available to the patient that has ac- 
ceptable risk to benefit ratios. And looking at the person that you're dealing with and trying to find out what makes the best solution for that individual whether or not it's a drug or a supplement or acupuncture or healing touch therapy, exercise. I mean it's almost always a combination of those things...I mean I think the baseline should be that we treat everybody with respect [and] everybody should have a wonderful experience.

And as Morris points out through a metaphor, IM doubles your work load:

In music, there's a thing that says enter through form and exit from form. And I think if you talk with a lot of artists, you have to learn...the rules before you can break them. And I...remain actually a very conservative physician. I remain very by the book. I think probably one of the most important things if there's anything that I try to impart to the residents, fellows, students that come through here is that IM means you're doubling your work, you're not cutting it in half. You are learning an entire other medical systems on top of what you should know and everything that you know that's the foundation of it.

While Morris articulates the work he accomplishes as an IM provider, his narrative also represents resistance to any simplification of IM.

A big part of the problem for IM providers is that when more emphasis is placed on disease care, it becomes difficult to implement and advocate for the strength of IM, which is communicating with the patient. One way this limitation shows up is in the restriction on the amount of time providers can spend with patients:

You know, 10-minute visits, 15-minute visits and it's ludicrous to me as someone trained in family medicine to say okay you're supposed to be the quarterback of this patient's team. You're supposed to coordinate their care, oversee their continuity of care, manage all of their chronic diseases, take care of all their preventive needs in a span of once a year 45minute annual visits and then in between have a 10, 15-minute visit...You know, this is a model that is not going to be sustainable in the long run. I'm hopeful that with the healthcare reform, there's really going to be a change.

A second way communication is limited is the electronic medical record, which demands that the provider stand at the computer, logging patient information, but as Iverson points out:

It's different, a little perhaps less personable than how we would have done things in the past, what we would catch one another, have an exchange with information. It's supposed to be more efficient but sometimes there are big holes in what's being recorded... It's like a barrier that often stands in between us and people that we try to communicate with.

A third way communication is limited circles back to the emphasis on disease-care and what can be reimbursed, as Halloway points out:

So this totally changes the incentives. The incentives right now are for me to do things to people. If I just put a pacemaker in you, a stent, a device, or even do a biopsy on your skin, I get paid a lot of money. If I say, talk to you about how to eat, exercise, and hear your life story, I get paid nothing, you know, so we're going to have a big shift in his country, and they're going to wake up, and they're going to go holy cow, where have we been?

Essentially, it is through communication that IM, disease-care and health-care, unite. It occurs in big and small moments where providers and patients communicate with one another. But as indicated by Hadley, the evidence for that value does not exist:

We don't show - we don't have the numbers, the data...It's the million dollar question [what is success], and we haven't created a way to capture that fully because it comes through interaction and verbally...We, as the staff, we know it, we recognize it because people will say, 'This is the best thing I ever did for myself,' or, 'You can imagine how much I've changed,' and from their point of view, they have. Recently one man told me, 'You know, you gave me an apple to eat one day when my blood sugar was low. I hadn't eaten an apple in 20 years and now I'm buying apples. 'How do you measure something like that?... Most of the feedback about success comes to us personally.

People have come to this on their own terms and on their own time, states Halloway. For all of these providers, disease care and health care belong together as a different model - they have come to it and hope that as health care reform takes places, others will too.

All nine providers talked about how the practices they engage in represent the value they place on integrating medicine, the ways they blend disease-care with healthcare. But they also spoke of the emphasis that the U.S. health care system places on disease-care - in terms of what is reimbursed and the lack of emphasis placed on and reimbursement for integration. They describe the difficulty of communicating and creating partnerships with other providers and patients because of the politics surrounding CAM and IM.

\section{Partnership with politics}

A second major tension that IM providers describe is one where they advocate for partnership with others in utilizing IM, but they describe how politics within the health care system interrupt or restrict that partnership. All nine providers would agree that if the IM partnership was strong, they could work together politically to advocate for IM within the larger health care system and for national health care reform. The words of providers help us to understand what they see as the composition of this tension.

Generally speaking, providers who only have disease- 
care in their tool bag AND don't partner with IM providers, miss out on what might be needed in providing health-care for the patient. This tension between partnership and politics plays out between IM providers and other medical doctors. Halloway puts it metaphorically this way:

They're saying... the fruit on the tree is sick. We're going to keep drugging it, doing surgery. We're saying the food is sick. Let's fix the soil. And they will say we agree with that, but they don't do it. They give it lip service.

One issue that stands in the way of creating a partnership with other providers is a lack of understanding about what IM is. Tali describes it in this way:

We're not doing anything special here, we're focusing on lifestyle and on nutrition and exercise. We're getting people-we're thinking outside the box if somebody doesn't want to do a stent then we'll say okay we will use supplements, you know? I mean I guess we don't believe this is rocket science. We believe this is the way you should do medicine.

Tali talks about his efforts to advocate for a partnership with other providers by attending a medical group meeting, asking them Hey, why don't you guys hire our acupuncturists. They looked at me like I had literally asked them if Mars was green.

A second issue that restricts the partnership with other medical doctors is the assumptions they make about IM. Some, for example, see IM as just one modality, for example acupuncture, as Halloway points out:

This is part of the confusion about IM because when they look here, they just think oh, it's about acupuncture. They don't realize it's about teaching people to eat, getting people exercising, helping people deal with their anger, their hopelessness, their stress, their depression, putting them together in community, all of which has beautiful research to support this, and the data supports it.

Other providers do not refer their patients to The Center, partner with IM providers, or advocate for IM because they do not see it as related to the work they do. As Carson points out:

But I would say we still have folks that either don't know about it, feel it's a separate silo or they have been negatively impressioned that this somehow is not quite what is the true clinical medicine. So they don't even mention it. So I think that is the key.

One reason they may not mention it has to do with an assumption a provider might make about a patient choosing IM as a replacement for biomedicine, as Halloway cautions:

So a lot of people in the beginning thought IM was about substituting things. You know, instead of my chemotherapy, I'll take herbs. Instead of my statin, I'll take red yeast rice. It's got nothing to do with that.

Carson suggests that advocacy work means that the IM providers need to consider how to build better bridges with all providers, especially the ones that see their work as unrelated to IM.

So it's not just a matter of helping the physician identify if this is the right patient or illness that would benefit from coming to The Center, but also getting that physician to realize that potentially all patients could benefit from that.

However, as the IM providers point out, building bridges can be difficult when there are still providers that battle the concept of IM by making notes in the medical record You know, this patient is doing supplements, which have never been proven and I needed to stop them now.

The tension between partnership and politics is also represented in the relationship between IM providers and patients and the lack of a support system for patients who seek IM. Iverson describes it as a stumbling block for patients trying to get to IM, but facing resistance from other providers:

Oh, there's plenty of resistance within the [health care] system. A lot of my patients say I really have to work hard to get to you even within the [health care] family...Because there's still plenty of physicians within the [health care] system even ones that have been here for more than a decade who still don't quite know that we exist or what do we do...So there's still a lot of ignorance that exists even within [the health care system] ... [Others are] more resistant to sending because they feel like there's still more that they could do. But the patient is like 'no, I don't want to have medications, I want to have these other alternatives' and they're like, 'No, no, you don't need to go over there, 'but they kept on persisting with it. It took them multiple visits with their primary care doctors to get them to be referred over to us.

In the end patients suffer when they are not able to get the health care they need or desire, and when providers don't understand or resist IM. Halloway speculates that a wide range of factors stand in the way of advocating for and providing the support system for patients to gain access to IM. In her view, it begins at the top:

If the senior administration doesn't understand what IM is about, it doesn't get that IM is about more efficient care that will cost less, focus on prevention, chronic disease management, then it will never go anywhere because they won't invest in it.

So partnership with administration is an important step in advocacy, but so too is the partnership with other providers, communicating the value that IM has for patients, as Halloway elaborates:

We have to recognize that there are global healing traditions in the world, right, and these global healing traditions are called traditional Chinese medicine, Ayurvedic medicine, homeopathy, naturopathy, allopathic medicine which is what I was trained to do with medical school. So all of these global healing traditions have value. It's only allopathic medicine that fo- 
cuses on disease. Every other global healing tradition says prevent the disease, right? The best physicians are the ones that prevent the disease in the first place. The providers in this study see advocacy for IM as advocacy for prevention and for managing the stress and depression that often accompanies disease. But as they point out, advocacy has been restricted by a lack of understanding of IM, assumptions others have made about IM, and even others feeling threatened by IM.

Politics is represented here in these stories through all the ways that people communicate to express or protect their interests. But if we begin to see politics as the art of making what appears to be impossible possible, ${ }^{39}$ then politics and partnerships become powerful ways to advocate for IM in health care systems and in health care reform. Our third and final category of communicating advocacy reveals the ways in which providers describe their efforts to form communities of support for IM.

\section{Advocacy is maintained through the formation of communities of support}

At the same time that providers acknowledge the ongoing dialectic tensions they must communicatively manage, they also talk about the ways they have been successful in forming communities of support. The notion of community articulated by the providers in this study frames health issues and IM within a capacities - rather within a deficits - perspective. ${ }^{4}$ These are represented in the stories of communicating advocacy through: i) a community of donors; ii) a community of providers; and iii) a community of patients.

\section{Advocacy through a community of donors}

All nine of the providers in one way or another speak to moments when they advocate for their foundational IM philosophy. In some ways, that is what our first category Providers' Resonance with the Mission of IM speaks to. But here it is more than the origins of or resonance with this philosophy; these are moments where the words of the providers describe the origins of The Center and what it took to advocate in ways that a community of donors could be established to guarantee its survival. The next two passages provide insight into the foundation of The Center's philosophy and the ways the two founders, Halloway and Lindholm communicated advocacy within the health care system and a community of donors. The words of Halloway describe the community created through their initial advocacy:

So Lindholm and I literally sat at her kitchen table and we said we can't just stop doing what we're doing. We can't at the end of this research say okay, study is over, no more yoga classes, no more exercise, no more cooking school. I mean we have created a community. People loved it. So we wrote the concept to creating a Center for IM and the vision that we came up with was healing people and changing lives through science and compassion. Because we wanted that combination of everything evidence based and yet coming from love and compassion. Coming from really connecting on the human level.

After they gained the verbal support from the CEO of the medical system, he indicated that he had no money to support them. But that did not stop Halloway and Lindholm. They relied on their community to advocate for the support they needed.

Because of our research, we had some very sick patients who also happened to be wealthy and they said we want you to continue this work and they began to fund us and support us. What started as a very, what we call bohemia, you know, just a couple of us in the basement downstairs and we had no chairs or desks but what we had was plenty of love and a lot of heart, you know, and the patients responded to that... We got patients to come in and paint murals on the wall so it didn't look like a blank wall. They came in and painted a beautiful mural. Everybody was sort of part of it, you know.

The community was very interested in finding $a$ way for the two paradigms to work together. Every single one of the providers told success stories, where their advocacy for IM paid off in terms of reaching people and convincing them of the value of their foundational philosophy. In the passage below, Lindholm speaks about one of those success moments when a large donation was offered after Halloway presented their idea.

So it was a very closed meeting only for these donors and administrators and so I sneaked in the back of the room and Halloway was already on the podium and this was live. So she puts the first slide and it had golden gate bridge and it was god preaching the alternative and conventional medicine. So... she put the slide up [and said] boy that's a bridge over troubled waters. And...everyone started laughing because it was - you know, Halloway is a good presenter...It was so tense...And in front of me were two doctors who I know I had worked for years, very conservative doctors and they were now in administration so when she was doing this and showing like what we were planning to do, one of them looked at the other and said boy she has guts and the other one goes 'yes'...So now we didn't know if she was going to get booed out or get the standing ovation. She did get a standing ovation and one man got up and said I have never heard anyone, any doctor ever talking like this, so I'm going to give for your dream. I'm going to give half a million dollars. Yeah. So Halloway said 'I don't know who you are but can I give you a kiss. So he had become a major donor'.

Along with advocacy being communicated by the founders through a community of donors who helped establish The Center and keep it running, advocacy was communicated through the community of providers. 
Advocacy through a community of physicians

All nine providers offered many examples of pivotal moments when they communicated advocacy for IM with each other or with physicians outside The Center. Each story built upon another with the underlying message that the community of IM supporters is growing. These are stories of success, of confidence, and of hope for the future of IM.

One central locale of this advocacy is within the community of providers that work with patients at The Center and believe in IM, as Iverson describes:

Well I envision it kind of a parallel track where we're able to spend some quality time in team building more on a person-to-person level not so much as physicians or nurses or whatever. Having that type of interaction to really have a more humanistic look at each person and then having some purposeful roundtable discussions on common problems that you see or some unusual problems that we don't see and how can we collaborate and have not necessarily a formulaic approach or some sort of flow chart, but maybe there are different ways of looking at the same problems by different people.

Halloway elaborates on her vision of how this collaborative community would communicate:

There's a once-a-week sit-down collaboration. The whole team sits in there... and discusses with the patient. And so you have the psychologist giving their input. You have the nutritionist giving their input, the nurses giving they input, exercise physiology is giving input. Everybody is discussing that patient, right? And that to me is the ideal.

While this is a vision of the ideal, one of the providers describes how he sees this vision of a collaborative community being enacted in part at The Center on a day-today basis:

It's all streamlined. So it's like when we see a patient and we say the need $X, Y$, and $Z$. Well $X, Y$, and $Z$ is right below us and so when they go down and they get their training or they get their physical therapy or cardiac rehab, that nurse can like instantly call me, page me and say 'Yo, I just got this person on the treadmill and they're not doing well.' So instantly I can know. I can even go down there and see. So there's always this communication going on with our patients...because we're kept in the loop. So it's good that we keep getting updates so that by the time we see them, we know they've been through all of this and we're ready to see them. We don't have to go hunting for what were the cardiac rehab results or what did the dietician say. It's all there.

In addition to communicating advocacy within the community of providers at The Center, the providers voiced their triumphs in collaborating with physicians outside The Center; they describe the advocacy that is communicated in a growing community of providers who are not trained in IM, but now see its benefits and legitimacy.

At times these pivotal moments focus on referrals and other times they focus on a particular patient another physician needs advice about. Halloway describes how she built The Center around Cardiology, but one day a physician from another specialty called her:

And then all of a sudden, a couple of years ago, I got a call from the head of the Cancer Center, and he said to me, 'Patient seems to think nutrition has something to do with cancer so can you provide us some nutrition classes?' I said, 'Absolutely. Happy to, 'you know, because it got to them, and now they say to me, 'Can you do a lecture on transforming stress on my body for cancer patients?'

This was a shift from physicians' earlier position when the IM providers sensed that the other physicians did not believe in what The Center offers. Carson described a similar pivotal moment:

I mean just this week there's been one doctor who's been here the whole 12 years I've been here, who I don't think has referred a patient, is sort of one of the old guard. And just this last week he...emailed me [about a] neuropathy patient where nothing has worked, 'Can you please see her?'I was like wow, we got to pick that up and get her in as soon as possible and make this as positive a case. Because that's what goes back and he says 'okay I don't know exactly what he did or what the techniques are or the herbs, but it helped and she's better, she's safe and nothing crazy happened so I'm going to send more folks'. I think that's the easiest way.

One provider and one patient at a time, providers communicate advocacy for IM, building a stronger and larger community of supporters. Several of the providers described how often that shift in perspective to believe in and support IM comes when a physician outside The Center becomes a patient, as described here by Tali:

So ... a week ago last Friday I had a neurologist call me up ... and she's like 'You know, I'm having palpitations. Do you mind seeing me?'So I said, 'Sure, come on over.' So she comes over. I spent about an hour with her. I went through everything but her palpitations, because it's everything else that causes it. So we spent a lot of time, she looks at me and she's like 'How do you do this? You spend all this time and you not once looked at the computer or look at your paper. You just talk to me.' And I'm like 'It's because that's what we do here. That's listening to your patient, that's the whole caring for the whole person, you know.' I'm like 'The palpitations are easy. I'll get a Holter, I'll get an echo, I'll test you for that. That's what I've been trained as a cardiologist to do. It's a harder to figure out why you're truly in this situation, what else is going on, what else could be contributing that kind of thing. I don't want to just give you pills.' 
She totally walked out with this epiphany...That's our best tool is to have other physicians experience it.

Advocacy occurred in this connection between the IM provider and the physician-patient; through communication and listening, a provider from outside The Center joined the community of supporters. Ultimately, this is the advocacy that most of the providers talked about a great deal - communicating advocacy with patients, one-byone, day in and day out.

\section{Advocacy through a community of patients}

Similar to their stories of pivotal moments with providers outside The Center, IM providers offered stories of pivotal moments with patients where they advocated for IM. While most often these are success stories of reaching, educating, or transforming a patients, one in particular was striking in terms of what it offered about the philosophy of IM and communicating with patients. Hadley told us about a psychologist that works within The Center, one-on-one with patients or conducting support groups for people in the intensive Lifestyle management program.

Phillips described one gentleman who we knew he wasn't getting it. He didn't get the connection. He did$n$ 't get the power of what the program could do for him. Phillips said he is on an island surrounded by a mote, and there's a wall. He's got a wall up in front of him, and there's broken glass on top of the wall. And you know, Phillips encourages us to hold everyone in the space of possibility of change, and who knows when. At some time in the future, something that man did here will strike a cord and we can't know how far down the road that might happen, if it does. But right now, any attempt to reach him over that high wall with broken glass on it, it isn't going to happen because he won't allow it. And it's a pretty neat space to work in when you can respect everyone's path...Phillips has given us one of our many mottos and that is we drip irrigate here. And if people aren't ready, it's okay, we'll respect that.

Drip-irrigating for Phillips is a process of educating, offering resources, support, and encouragement, and opening spaces for them to discover what changes they can make. This was the case for a patient of Carson's named Carol:

We have a number of those patients who bounced between myself and...other pain specialists...[She] had been seen by me over ten years as well as multiple other doctors for injections, medications, fibromyalgia, low back pain. She was in a wheeled scooter. And what the collaboration taught me was it was failing. Like everyone was doing things to her and she wasn't doing anything for herself and we're enabling that. [Carol came back] four months ago and she's morbidly obese...I said we have to stop talking about the pain and start talking about your metabolic workings...So she was one of our first new clients for this I-fit care model where she wears... a body media brace on her arm that tells her caloric burn rate 24/7... Me the dietician, the exercise physiologist, the behaviorist all can see that, you know, real time. And we can give her suggestions online and she's lost 50 pounds in a ...rational period of time after entire life of never being able to lose significant weight or keep it off... Until the patient was brought back in and said the real issue is can we get your lifestyle back in order and [now] she's out of the scooter, she's running on a treadmill. She actually volunteers downstairs to enroll new clients for us.

In the process of advocating for this one patient, Carson has helped this patient to become an advocate for other patients, supporting them toward the kind of success that she has had and expanding the community of patients who advocate for IM. Carson tells us about studies of patient satisfaction with IM and what they find is that it is $a$ lot about the communication and the connection and not being rushed.

Communicating advocacy for IM is accomplished in a multitude of ways. The stories of providers in this study reveal that it begins with providers' resonance with the mission of IM, something that may occur when they are young, in their families, or even because of a pivotal moment in their personal lives. Communicating advocacy is not always an easy task, especially when providers face systemic dialectic tensions that they must manage in their medical practice of integrating their biomedical expertise with their CAM expertise. Finally, and possibly most significantly, communicating advocacy is accomplished through communities of supporters - health administrators, donors, providers outside The Center, and every single day, with patients. Pivotal moments, epiphanies, vison, connections, and daily drip-irrigation are all important for communicating advocacy for IM.

\section{Discussion}

This research focuses on the narratives of IM providers and what they revealed about communicating advocacy. First, advocacy narratives often begin with turning point moments involving family members and their health. Participants relied on past histories and familial memories to construct narratives that revealed the emergence of their initial interests to study IM. Nearly every participant told stories that involved being drawn to IM philosophies at an early age after being influenced by a family member, including: grandparents' philosophy of life (Hughes), parent's teaching of healthy practices (Iverson), a father's career as a botanist (Silverman), a father's illness and death (Tali), and a mother's early death (Halloway). Second, the results revealed that providers engage in advocacy through a continuous process of communicating to manage tensions and contradictions that arise in a health care system that has not fully embraced 
IM. Finally, the results revealed the importance that IM providers place on communicating in ways that construct a community of professionals who advocate for IM. In the subsections that follow, we offer conclusions that we draw from these results, theoretical and practical implications of the results, and the directions for future research.

\section{Conclusions}

Providers' narratives offer insights about the significant role that advocacy for IM plays in family communication, professional communication, and in provider-patient communication. Two predominant conclusions can be drawn from these results. First and foremost, providers' narratives reveal that advocacy is centered on patients. This is not surprising, since patientcenteredness is a cornerstone of IM as a health care philosophy and approach. The results reveal that IM providers not only treat their patients with an integration of biomedicine and holistic therapies, but also strive to empower patients to take an active role in their health management; this is a tenant that aligns with the notion that IM patients are given the agency to take control of their own health. ${ }^{30}$ We see this through Tali's story of meeting with a coworker and neurologist experiencing heart palpitations, as well as Carson's narrative surrounding Carol, a patient who has had appointments at The Center for over a decade and has since become a volunteer to help with IM client enrollment. The story of Carol is particularly powerful when considering how advocacy functions on a relational level, where her experience of healing through IM helped her to become an advocate for prospective IM patients. Although provider advocacy narratives often center around success stories with patients with the central mission of getting physician [s] to realize that potentially all patients could benefit from [IM], being an advocate of IM also involves being content with patients who are not convinced of the merits of IM: if people aren't ready, it's okay, we'll respect that. Therefore, IM providers' narratives of advocacy often focus on patient stories and the role the providers play in changing patients' lives.

A second conclusion that can be drawn from the results of this study is the need for innovative changes in the ways that medicine is practiced in the U.S. While these providers' personal histories provided an invaluable foundation to draw upon in communicating advocacy for IM, they all faced structural roadblocks everywhere throughout the health care system. For one, the way that medicine is practiced often creates a series of silos based upon specializations, where communication and advocacy is restricted. The providers in this study spoke to the difficulty of reaching physicians and patients who are localized in specific specialties such as cancer, rheumatology, neurology, and many others; advocacy for most of the providers in this study meant preaching to the choir of people who already believed in or were curious about IM. Second, The Center is decentralized and segregated from the other locations of this health care system. While some of the physicians believe that there may be value for patients in centralizing IM so that it is offered at every one of the five campuses, practically this would be difficult, not only in terms of staffing each with sufficient CAM modalities, but also because of the limited number of IM providers that work within the system. Third, and finally, the organization of the U.S. health care system does not facilitate the building of relationships with physicians. While this may be a goal for both providers and patients, especially in advocating for IM, it is often restricted by appointment time limitations, lack of continuity in Health Maintenance Organizations for consulting with the same physician at each appointment, and lack of reimbursement for CAM modalities in most health care plans.

While these two conclusions offer insight into the communicative processes that participants engage in to advocate for IM, a range of theoretical and practical implications for IM advocacy can be drawn from these results.

The results of this investigation offer a number of implications for theory; we will focus on two: narrative medicine and dialectic theory.

First, as a study that focuses on narrative, this investigation revealed that IM providers offer stories of their experience with patients that reveal their narrative competence. Halloway tells us that the book she has published is based on the true stories of patients whose lives changed drastically because of their use of IM. As well, all nine providers reveal in some way that they are practicing narrative medicine with empathy, reflection, and professionalism. Rita Charon, MD suggests that along with scientific ability, physicians need the ability to listen to the narratives of the patient, grasp and honor their meanings, and be moved to act on the patient's behalf ( $\mathrm{p}$. 1897). ${ }^{40}$ Tali tells the story of spending an hour treating another physician, and her asking how she does it - spend this much time, not look at the computer, and just talk. Tali responds by saying It's because that's what we do here. That's listening to your patient, that's the whole caring for the whole person. Narrative medicine is growing in popularity, especially through the work of Charon ${ }^{41}$ and colleagues in the Program in Narrative Medicine at Columbia University. ${ }^{42}$ However, it is important to consider the larger structural inequalities in our health care system that may constrain providers' abilities to enact narrative medicine, no matter how much they advocate for it. ${ }^{43}$ As well, it is sometimes difficult for people to listen in $s o$ cially just ways...to listen to stories that challenge them, stories that are from the margins, stories that are traditionally silenced. ${ }^{44}$ Sayantani DasGupta, MD suggests that providers need narrative humility so that they may improve relationships with patients, deepen their listening, deepen their medical practice, and become more accurate and effective at their diagnosis and treatment. 
A second important theoretical implication is tied to dialectic theory, which relates to the contradictions or tensions that people may experience as they communicate with one another in relationships. ${ }^{45}$ As our results revealed, communicating advocacy is often complicated by tensions between disease care and health care, between partnerships and politics, between science and compassion, and between education and cost. These dialectic tensions fold into one another in ways that complicate communication and advocacy. This is especially the case because of how providers' stance within these dialectic tensions is very much tied to their professional and personal identities, further limiting their communication of advocacy for IM.

The stakeholders that might find valuable insight from the providers' narratives in this research may include other providers, health administrators, and of course patients and their families. We learn through this study that advocacy is never easy; therefore, the two practical implications we offer are tied to what we learned from providers about enacting advocacy.

One practical implication of this research is that even though all the providers in this study described personal or familial histories that created a strong foundation for their philosophy and practice of IM, translating that philosophy to strategies for communicating advocacy was a hit and miss process of learning the power of the story. Providers in this study lamented the fact that currently there is no system in place for documenting the success stories of IM. While dialogue has ensued about the ways that CAM can be evidence-based medicine throughout the U.S. ${ }^{46,47}$ most health care systems have not developed or implemented systems for documenting evidence of the success of CAM and IM. Providers in this study suggest that advocacy for IM will take off and be much easier to accomplish with more intensive publication of scientific evidence of its value, not just in terms of clinical randomized trials, but in the systematic documentation of patients' stories of the value of IM.

One way of accomplishing this documentation is through studies such as this one. The providers in this study initially were hesitant to share details of their experiences with IM, including some of their specific concerns with the organization and functioning of The Center. Yet, with time and rapport, each participant began to share ideas, that they had never verbalized before. Over the course of the interview, providers' descriptions eventually began to deepen and reflections became more vivid.

Therefore, a second practical implication of this research is for health care systems to create specific opportunities for providers to share their advocacy narratives. These opportunities would offer providers a chance to reflect, interrogate, and visualize collectively. In this way, communication of advocacy within the health care system may alleviate some of the problematics IM providers have encountered, including assumptions that IM providers are competing with their specialty, IM providers are stealing patients, or IM providers are quacks, grass pushers or herbal freaks. In this way, health care providers, along with other members of their communities, could begin to uncover new motivations and opportunities for advocacy. Additionally, since providers favor stories about patients when communicating advocacy, IM physicians might learn more about their own identity as an advocate by inviting patients to share narratives of their experiences with IM. There is merit in discovering how patients advocate for IM similarly or differently from providers, and how IM practitioners can refine their own advocacy messages through conversations with patients about their own stories of advocacy with families and friends. These theoretical and practical implications speak to the insights offered by the results of this study; as well, it is insightful to consider potential directions for future research.

First, future research could investigate the communication of advocacy by IM providers across facilities, regions, and countries to learn how they may be similar or different from the experience of these providers. Investigating the stories of IM providers with different histories, biomedical specialties, and CIM modalities would offer a comprehensive understanding of how IM is approached, constructed, and advocated for within the health care community.

Second, insights could be gained by hearing the voices of administrators staffing the local health care system, but also the voices of health care policy makers and administrators of the national health care system. Future research could offer insights by including these voices, either through interviews or through participant observation. It would be fascinating to explore how patients and providers co-construct advocacy during interactions and how patients become agents and advocates of their own health care. Future studies surrounding IM advocacy should therefore incorporate other voices and narratives from the various stakeholders and health care workers that are involved in the day-to-day functions of The Center, including administrators, nurses, technicians, and assistants.

IM is an approach to health care that has become part of nearly one-third of American's lives. ${ }^{10}$ While several studies have revealed patients' communication strategies surrounding IM, we hope to pave new ground in understanding what IM providers' narratives reveal about the ways in which advocacy is constructed and communicated. If the hope of IM providers is to offer IM through every health care system and every insurance provider, we must learn more about the communication of advocacy - where it begins and how it is constructed by the providers who intend to help us heal.

\section{References}

1. Rakel D. Integrative Medicine. Philadelphia, PA: Elsevier; 2018.

2. Weil J. The holistic attitude in medical consultation. Am Pract Diag Treat 1952;3:1. 
3. Baer HA. Toward an integrative medicine. Walnut Creek, CA: Alta Mira; 2004.

4. Geist-Martin P, Ray EB, Sharf BF. Communicating health: Personal, cultural, and political complexities. Long Gove, IL: Waveland Press; 2011.

5. The Bravewell Collaborative. What is integrative medicine? 2011. Available from: http://bravewell.org/integrative medicine/

6. Horrigan B, Lewis S, Abrams DI, Pechura C. Integrative medicine in America: How integrative medicine is being practiced in clinical centers across the United States. Global Adv Health Med 2012;1:18-94.

7. Geist-Martin P, Sharf BF, Jeha N. Communicating healing holistically. In: Zoller H, Dutta M, eds. Emerging perspectives in health communication: Meaning, culture, and power. New York, NY: Routledge; 2008. pp 85-112.

8. Ho EY, Bylund CL. Models of health and models of interaction in the practitioner-client relationship in acupuncture. Health Commun 2008;23:506-15.

9. National Center for Complementary and Alternative Medicine. Complementary, alternative, or integrative health: What's in a name? 2016. Available from: http://nccam.nih.gov/

10. Clarke TC, Black LI, Stussman BJ, et al. Trends in the use of complementary health approaches among adults: United States, 2002-2012. Natl Health Stat Rep 2015;79:1-16.

11. Fadlon J. Negotiating the holistic turn. Albany, NY: State University of New York Press; 2005.

12. Alster KB. The holistic health movement. Tuscaloosa, AL: University of Alabama Press; 1989.

13. Geist-Martin P, Bollinger BJ, Wiechert KN, et al. Challenging integration: Clinicians' perspectives of communicating collaboration in a center for integrative medicine. Health Commun 2016;31:544-56.

14. Gaboury I, Lapierre LM, Boon H, Moher D. Interprofessional collaboration within integrative healthcare clinics through the lens of the relationship-centered care model. J Interprof Care 2011;25:124-30.

15. Barrett B. Alternative, complementary, and conventional medicine: Is integration upon us? J Altern Compl Med 2003;9:417-27.

16. Keshet Y, Ben-Arye E, Schiff E. Can holism be practiced in a biomedical setting? A qualitative study of the integration of complementary medicine to a surgical department. Health 2012;16:585-601.

17. Keshet Y, Ben-Arye E, Schiff E. The use of boundary objects to enhance interprofessional collaboration: Integrating complementary medicine in a hospital setting. Sociol Health Ill 2013;35:666-81.

18. Checton MG, Greene K, Carpenter A, Catona D. Perceptions of health information seeking and partner advocacy in the context of a cardiology office visit: Connections with health outcomes. Health Commun 2017;32:587-95.

19. Rafferty KA, Sullivan SL. 'You know the medicine, I know my kid': How parents advocate for their children living with complex chronic conditions. Health Commun 2017;32: 1151-60.

20. Isgro K. From a caretaker's perspective: Mothers of children with Down syndrome as advocates. Women Lang 2015;38:63-82.

21. Borofka KE, Boren JP, Ellingson LL. 'Kind, sensitive, and above all, honest': Long-term cancer survivors' quality of life and self-advocacy. Commun Res Rep 2015;32:373-8.

22. Brashers DE, Haas SM, Klingle RS, Neidig JL. Collective
AIDS activism and individuals' perceived self-advocacy in physician-patient communication. Human Commun Res 2000;26:372.

23. Kleinert JO, Harrison EM, Fisher TL, Kleinert HL. 'I can' and 'I did': Self-advocacy for young students with developmental disabilities. Teach Except Child 2010;43:16-26.

24. Brandhorst JK, Jennings FJ. Fighting for funding: Values advocacy and planned parenthood's right-to-life. Pub Relation Rev 2016;42:723-33.

25. McKeever B. From awareness to advocacy: understanding nonprofit communication, participation, and support. J Pub Rel Res 2013;25:307-28.

26. Sharf BF, Geist-Martin P. Integrative medicine. In: Thompson T, ed. Encyclopedia of health communication, Vol II. Thousand Oaks, CA: Sage; 2014. pp 727-729.

27. Busse JW, Heaton G, Wu P, et al. Disclosure of natural product use to primary care physicians: A cross-sectional survey of naturopathic clinic attendees. Mayo Clin Proc 2005;80:616-23.

28. Robinson A, McGrail MR. Disclosure of CAM use to medical practitioners: A review of qualitative and quantitative studies. Complement Ther Med 2004;12:90-8.

29. Ho EY, D'Agostino TA, Yadegar V, et al. Teaching patients how to talk with biomedical providers about their complementary and alternative medicine use. Patient Educ Counsel 2012;89:405-10.

30. Willard BE. Feminist interventions in biomedical discourse: An analysis of the rhetoric of integrative medicine. Women's Stud Commun 2005;28:115-48.

31. Harter LM, Bochner AP. Healing through stories: A special issue on narrative medicine. J Appl Commun Res 2009; 37:113-7.

32. Servaes J, Malikhao P. Advocacy strategies for health communication. Pub Relation Rev 2010;36:42-9.

33. Tracy SJ. Qualitative research methods: Collecting evidence, crafting analysis, communicating impact. Malden, MA: Wiley-Blackwell; 2013.

34. Robert D, Shenhav S. Fundamental assumptions in narrative analysis: Mapping the field. Qual Rep 2014;19:1-17.

35. Sharf BF, Geist-Martin P, Cosgriff-Hernandez KK, Moore J. Trailblazing healthcare: Institutionalizing and integrating complementary medicine. Patient Educ Counsel 2012;89: 434-8.

36. Rogier Hoenders HJ, Appelo MT, de Jong JTVM. Integrative medicine: A bridge between biomedicine and alternative medicine fitting the spirit of the age. Sociol Mind 2012;2: 441-6.

37. Todorov T. Theories of the symbol. Ithaca, NY: Cornell University Press; 1984.

38. Waitzkin H. The second sickness: Contradictions of capitalist health care. Lanham, MD: Rowman \& Littlefield; 2000.

39. Rodham H. Student commencement speech, Wellesley College. Wellesley, MA; 1969.

40. Charon R. Narrative medicine: A model for empathy, reflection, profession, and trust. JAMA 2001;286:1897-902.

41. Charon R. Narrative medicine: Honoring the stories of illness. New York, NY: Oxford University Press; 2008.

42. Charon R, DasGupta S, Hughesn N, et al. The principles and practice of narrative medicine. New York, NY: Oxford University Press; 2016.

43. Ensign J. The problem(s) with narrative medicine. 2014. Available from: https://josephineensign.com/2014/07/16/the-problems-with-narrative-medicine/ 
44. DasGupta S. Narrative medicine, narrative humility: Listening to the streams of stories. Creative Nonfiction: True Stories, Well Told 2014;52. Available from: https://www.creativenonfiction.org/online-reading/narrative-medicine-narrative-humility.

45. Baxter LA, Montgomery BM. Relating: Dialogues and di- alectics. New York, NY: Guilford; 1996.

46. National Center for Complementary and Integrative Health. Evidence-based medicine: Literature reviews. 2017. Available from: https://nccih.nih.gov/health/providers/litreviews.htm.

47. Yamey G. Can complementary medicine be evidence-based? West J Med 2000;173:4-5. 